\title{
Argumentações de um grupo de professores acerca do uso de atividades investigativas
}

\section{Arguments of a group of teachers about the use of investigative activities}

\author{
Joici de Carvalho Leite (joicicarvalho@hotmail.com) \\ Universidade Estadual de Maringá (UEM); Doutoranda do Programa de Pós-Graduação em Educação \\ para a Ciência e a Matemática (PCM); Grupo de Pesquisa em Ensino de Ciências, Formação de \\ Professores e Representações Sociais (CIENCIAR)
}

\author{
Carlos Alberto de Oliveira Magalhães Júnior (juniormagalhaes@hotmail.com) \\ Universidade Estadual de Maringá (UEM); Professor Adjunto do Departamento de Ciências (DCI); \\ Programa de Pós-Graduação em Educação para a Ciência e a Matemática (PCM); Grupo de Pesquisa em \\ Ensino de Ciências, Formação de Professores e Representações Sociais (CIENCIAR) \\ Maria Aparecida Rodrigues (aparecidar@gmail.com) \\ Universidade Estadual de Maringá (UEM); Programa de Pós-Graduação em Educação para a Ciência e a \\ Matemática (PCM)
}

\begin{abstract}
Resumo:
Este artigo versou sobre os resultados parciais de uma pesquisa de mestrado, que teve como objetivo averiguar as reflexões um grupo de estudos composto por dez participantes, sobre o uso de atividades investigativas no ensino de ciências. Assim, mediante a leitura de artigos, e a realização de atividades envolvendo a temática em questão, o grupo foi instigado a responder questões referentes a este tipo de ensino. Os dados foram coletados por meio de gravações em áudio e respostas a um questionário e analisados de acordo com o embasamento teórico de autores que defendem o uso de atividades investigativas nas aulas de Ciências. Com os resultados obtidos infere-se que uma parcela expressiva dos participantes da pesquisa apresentou uma visão tradicional em relação ao ensino de ciências e, também, certa resistência ao uso de atividades investigativas. Entretanto, com o desenvolvimento das atividades do grupo, um ambiente de reflexão foi estabelecido dando abertura para a aceitação e construção de conhecimentos científicos de cunho investigativo, contribuindo significativamente na formação continuada do grupo de professores.
\end{abstract}

Palavras-chave: Ensino por investigação; Formação continuada; Grupo de estudos.

\begin{abstract}
:
This paper deals with on the partial results of a master's research, aimed to objective to investigate the reflections a group of studies composed of ten participants, on the use of investigative activities in science teaching. Thus, through the reading of articles, and the realization of activities involving the theme in question, the group was instigated to answer questions regarding this type of teaching. Data were collected through audio recording and responses to questionnaires and analyzed according to the theoretical
\end{abstract}


background of authors who defend the use of investigative activities in science classes. With the results obtained we infer that an expressive part of the research participants presented a traditional view regarding science teaching and, also, some resistance to the use of investigative activities. Though, with the development of the group's activities, a reflection environment was established by opening up the acceptance and construction of scientific knowledge of an investigative nature, contributing significantly to the continuing formation of the group of teachers.

Key words: Science education; Continuing education; Group of studies.

\section{INTRODUÇÃO}

O ensino de ciências pode proporcionar aos alunos da educação básica muitas indagações e desafios, contudo em algumas ocasiões ele é caracterizado pela dificuldade dos estudantes em relacionarem as teorias aprendidas em sala de aula com o ambiente no qual estão inseridos. Estudos indicam que essa categoria de ensino tem sido de caráter transmissivo e aportada na memorização desde a sua implantação no sistema de ensino brasileiro, em meados da década de 1930 (MAGALHÃES JÚNIOR; PIETROCOLA; ORTÊNCIO FILHO, 2011).

Segundo Carvalho (2013, p. 8), "introduzir os alunos nas diversas linguagens das Ciências é, na verdade, introduzi-los na cultura científica". Em contrapartida, Delizoicov, Angotti e Pernambuco (2002) discorrem que a maioria dos resultados provenientes de algum tipo de atividade científica é pouco disseminada no ambiente escolar e, por isso, passível de uso e compreensão errônea e até mesmo ingênua. Nesse caso, se faz necessário a proposição de um ambiente investigativo em sala de aula, no qual seja possível mediar os alunos em um processo que viabilize o trabalho científico para que a cultura científica seja adquirida no dia a dia (SASSERON; CARVALHO, 2008).

Nesta perspectiva, discutem-se no artigo em questão, resultados parciais de uma pesquisa de mestrado, que teve como objetivo averiguar as reflexões de um grupo de professores acerca do uso de atividades investigativas no ensino de ciências. Em meio às respostas foi possível planejar atividades visando à contribuição no processo de formação continuada destes docentes, bem como na elaboração de conhecimentos sobre 
o ensino por investigação, orientando os participantes na elaboração de aulas, atividades e sequências didáticas.

\subsection{O ensino de Ciências no Brasil}

Nas últimas décadas o cenário educacional vem sofrendo significativas transições em virtude das profundas mudanças sociais, culturais e econômicas. Com essa recente realidade, nota-se o crescente debate sobre novas práticas pedagógicas que possam contribuir para melhorias no ensino de ciências. Dentre essas práticas destaca-se o ensino por investigação, considerado imprescindível por diversos professores/pesquisadores para a evolução do ensino de ciências.

Essa inquietação pedagógica revelou seus primeiros sinais na segunda metade do século XIX, com a ascensão de diversas tendências de ensino de ciências na Europa e nos Estados Unidos que passaram a considerar os aspectos políticos, históricos e filosóficos (ZÔMPERO; LABURÚ, 2011). Ainda conforme os autores, no Brasil a grande maioria dessas tendências não ganhou destaque, com exceção ao ensino por investigação.

$\mathrm{Na}$ realidade a inserção do ensino por investigação no Brasil ocorreu com as teorias da educação progressiva de John Dewey, inseridas pelo Manifesto dos Pioneiros durante os anos de 1930, baseado na fundamentação da pedagogia construtivista dos trabalhos de Jean Piaget e Lev Vygotsky (BORGES, 2010). O filósofo John Dewey é considerado por muitos estudiosos como uma forte influência da educação norteamericana com sua perspectiva de inquiry (descoberta), que passou a levar em consideração os valores sociais para a resolução de problemas (OLIVEIRA, 2013).

Em países como a Inglaterra e os Estados Unidos o ensino por investigação já faz parte de seus currículos de ciências há vários anos (SÁ, 2009). Todavia, no Brasil os Parâmetros Curriculares Nacionais - PCN (1998), documento orientador para o ensino fundamental e médio, não traz orientações que possam corresponder a essa abordagem. Oliveira (2013, p. 83) expõe que: “[...] não há nesses documentos qualquer destaque ou menção direta ao ensino de ciências por investigação como uma das propostas de ensino e aprendizagem em Ciências". No entanto, o autor entende que, nas orientações metodológicas em torno dos eixos temáticos para o ensino fundamental ( $6^{\circ}$ ao $9^{\circ}$ ano), 
existem algumas considerações que remetem ao ensino investigativo.

Apesar de não contar com nenhuma menção clara nos documentos oficiais, atualmente, a temática investigativa ganhou uma abertura expressiva no Brasil, embora ainda exista muito que ser pesquisado e explorado. De tal modo, uma definição única do termo ainda está em vias de lapidação, Munford e Lima (2007) ponderam que ao se falar sobre o tema busca-se uma promoção diferenciada, a respeito do ensino de ciências, no qual o ensino tradicional pautado na memorização seja excluído, dando abertura para o ensino que saiba representar aspectos da prática científica. Segundo esses autores, “[...] na escola os conceitos são apresentados de forma abstrata e distanciados do contexto que lhe deram origem" (MUNFORD; LIMA, 2007, p. 91). Ou seja, em seu artigo os pesquisadores concordam que existem duas ciências, a dos cientistas e a escolar.

Sob essa perspectiva é necessário um ensino que relacione conceitos científicos e de aprendizagem, destacando o papel do aluno como sujeito principal no processo de ensino e do professor com mediador desse processo. Nas palavras de Zômpero e Laburú (2012, p. 676) "essa abordagem propõe-se um ensino em que o aluno tenha um papel intelectual bastante ativo na construção de seu conhecimento. O foco dessa metodologia não fica restrito apenas à aprendizagem dos conteúdos disciplinares".

\subsection{Atividades Investigativas nas Aulas de Ciências}

Durante muitos anos, as informações foram "transmitidas" aos alunos somente pela exposição dos professores. Conforme Carvalho (2013), no ensino de ciências, os alunos repetiam experimentos por meio de um protocolo e decoravam nomes científicos, os exercícios eram apenas de memorização e de localização no livro didático. Agora tem-se um volume muito grande de conhecimentos, e "[...] não é possível ensinar tudo a todos [...]. Valorizou-se a qualidade do conhecimento a ser ensinado e não mais a quantidade" (CARVALHO, 2013, p. 1).

Na vertente investigativa, a dinâmica é diferenciada, porque o professor assume a função de mediador do conhecimento científico, instigando seus alunos com questões problematizadoras e desafiadoras. Os alunos por sua vez, buscam formular hipóteses, 
através de pesquisas, questionamentos, interações, sempre orientadas pelo professor (LEITE, MAGALHÃE JÚNIOR; RODRIGUES, 2016).

Na percepção de Oliveira (2013), o objetivo das atividades investigativas não é formar cientistas e, sim, fazer com que o aluno tenha um olhar crítico sobre o que está sendo apresentado, e que a aquisição de conhecimento seja o objetivo central de todo o processo.

É valido destacar, que as atividades investigativas devem proporcionar aos alunos o contato com novas informações para que o conhecimento de senso comum seja substituído pelo científico. "O docente deve deixar que a liberdade intelectual de seus alunos venha à tona, e que a edificação do conhecimento seja atingida gradativamente, sempre com o auxílio do professor" (LEITE, 2015, p. 2). Nesse mesmo embasamento teórico Azevedo (2008, p. 31) discorre que:

A atividade investigativa, portanto, não é nada mais do que a busca pela solução de um problema dito de "ensino" ou de "aprendizagem", com a intenção de levar os sujeitos envolvidos à aprendizagem por meio da construção de conhecimentos. O problema, a necessidade e o motivo são os elementos essenciais que identificam a atividade investigativa e que garante a instauração do processo investigativo.

Por esse olhar, a autora aponta a essencialidade do problema em uma atividade investigativa, pois se esse não for claro e não suscitar no aluno a busca do conhecimento, não se obterá um resultado satisfatório em termos de um processo investigativo e de aprendizagem.

Carvalho (2004) expressa que quando o professor decide fazer o uso de atividades investigativas em suas aulas, ele não deve limitar seus alunos a conceitos específicos, ou ao simples manuseio de dados e experimentações regidas por protocolos. $\mathrm{Na}$ visão da autora, esse tipo de atividade demanda do aluno um esforço interpretativo e também (re) interpretativo na busca de uma solução adequada ao problema proposto, o que acarreta planejamento, registro e análise dos dados.

Assim, nas aulas norteadas pelo ensino investigativo, o professor e o aluno são envolvidos em argumentações constantes. Sasseron (2013) e Sasseron e Letta (2017) defendem que, por meio dos debates em sala de aula, os conhecimentos científicos vão se formando, pois as discussões propiciam aos alunos a reflexão e troca de ideias. Em 
aulas baseadas na metodologia investigativa, todos os pormenores devem ser valorizados, pois podem conferir caminhos para o desenvolvimento do trabalho. Por essa razão, é importante que o professor possa promover aulas interativas, no qual todos possam expressar o que entenderam, observaram e também, suas dúvidas, sempre mediados pelo. É oportuno salientar que, “[...] essas interações discursivas devem ser promovidas pelo professor e cuidados precisam ser tomados para que o debate não se transforme em uma aula banal" (SASSERON, 2013, p. 43).

Diante destas considerações, destaca-se a importância do ensino de ciências pautado em atividades investigativas, como capaz de promover a autonomia, a curiosidade, a socialização e o desenvolvimento do senso crítico dos alunos na elaboração do conhecimento científico.

\subsection{Formação Continuada de Professores de Ciências}

A atividade docente não pode e nem deve ser isolada, pois, o saber discutido em conjunto deixa de ser obstáculo e passa a ser inovação e perspectiva (CARVALHO; GIL-PÉREZ, 2011). Nessa lógica, o professor necessita, constantemente, ser convidado a uma reflexão sobre novas propostas e metodologias de ensino, que venham a contribuir de maneira efetiva para sua formação continuada.

“A formação continuada é um processo de aprendizagem e de socialização, de natureza voluntária, informal e pouco previsível, que está centrado na interação entre colegas e nos problemas que trazem de suas práticas docentes" (SCHNETZLER, 2002, p. 16). Para a autora, uma formação continuada só é efetiva quando ocorre a socialização dos saberes; por isto, entende-se que os grupos de estudos proporcionam aos docentes um compartilhamento de experiências reais com discussões sobre o universo escolar. Além do mais, a formação de grupos de estudos criam ambientes de solidariedade entre os participantes, uma vez que, por meio do diálogo, todos podem perceber os problemas dos outros, criando oportunidades para a busca de soluções em conjunto.

Garcia (1999, p. 26) explana que a formação de professores é uma área de conhecimentos e investigações de suma importância, pois nesse processo os professores 
buscam novos conhecimentos, além de refletirem sobre aqueles adquiridos durante a formação inicial. O autor infere que:

\begin{abstract}
A Formação de Professores é a área de conhecimentos, investigações e de propostas teóricas e práticas que, no âmbito da Didática e da Organização Escolar, estuda os processos através dos quais os professores - em formação ou em exercício - se implicam individualmente ou em equipe, em experiências de aprendizagem através das quais adquirem ou melhoram os seus conhecimentos, competências e disposições, e que lhes permitem intervir profissionalmente no desenvolvimento do seu ensino, do currículo da escola, com o objetivo de melhorar a qualidade da educação que os alunos recebem.
\end{abstract}

Nessa mesma vertente Libâneo e Pimenta (1999, p. 261) exprimem a necessidade de "[...] uma escola que inclua $[. .$.$] com qualidade, superando os efeitos perversos das$ retenções e evasões, propiciando-lhes um desenvolvimento cultural [...]”. Porém, para que esta escola "aconteça", necessita-se de professores preparados e dispostos a compartilhar seus saberes específicos, mesmo enfrentando todas as dificuldades que podem surgir dentro e fora de uma sala de aula. Assim, nessa difícil jornada, o professor carece de condições de trabalho, salariais, formação inicial e continuada de qualidade e, sobretudo, valorização.

\title{
2. PROCEDIMENTOS METODOLÓGICOS
}

O presente artigo expõe resultados parciais de uma pesquisa de mestrado, apresentada ao Programa de Pós-Graduação em Educação para a Ciência e a Matemática do Centro de Ciências Exatas da Universidade Estadual de Maringá (PCM/UEM) desenvolvido no período de 2013 a 2015.

A pesquisa é de natureza qualitativa, por apresentar indagações subjetivas, sem quantificações, pois abarcou um vasto universo de significados, em consonância com Minayo (1996). Foi realizada no ano de 2014, em um contexto de grupo de estudos intitulado "ensino por investigação em ciências", que ocorreu quinzenalmente, nas dependências da Universidade Estadual de Maringá (UEM), somando uma carga horária de 32 horas, dividida em oito encontros.

O grupo contou com a participação de sete professores de Ciências, um professor de Química e dois estudantes de licenciatura em Química, totalizando dez participantes, oriundos respectivamente, da Rede Estadual de Ensino do Estado do Paraná e da UEM. 
Em relação ao tempo de experiência docente: dois professores possuíam 30 anos, quatro professores entre 20 e 25 anos, um professor com 12 anos de experiência e dois licenciandos em Química sem experiência docente. Quanto à formação, todos os participantes, com exceção dos discentes no curso de Química, possuíam uma graduação e uma pós-graduação na área de ensino. Há que se considerar que os dois participantes licenciandos, solicitaram a participação no grupo espontaneamente, e possuíam experiência em projetos de ensino, como o Programa Institucional de Bolsa de Iniciação à Docência (PIBID) e estágio em colégios da rede pública de ensino, por isso foram considerados como professores, mesmo que em formação.

Os dados foram coletados por meio de gravação em áudio (autorizadas pelos professores) com posterior transcrição e ainda, respostas a um questionário. É válido destacar, que a pesquisa em questão foi aprovada pelo Comitê de Ética da Universidade Estadual de Maringá (COPEP/UEM), sob o parecer n. ${ }^{\circ}$ 548.275/2014, e autorizada à divulgação dos resultados pelos seus participantes, que foram identificados apenas com letra $\mathrm{P}$ e com um número variando de 1 a 10.

Nos encontros foram discutidos com os integrantes do grupo alguns textos e artigos, que versavam sobre: o ensino de ciências, o ensino de ciências por investigação e a elaboração de sequências didáticas. Dentre os artigos, o escolhido para esta análise foi: "Implementação de atividades investigativas na disciplina de Ciências em escola pública: Uma experiência didática” de Andreia de Freitas Zômpero e Carlos Eduardo Laburú $^{1}$, do ano de 2011. O artigo aborda uma atividade investigativa sobre fotossíntese e respiração, realizada em uma escola pública, de periferia, do município de Londrina no Estado do Paraná. A turma pesquisada era composta de 32 alunos do $6^{\circ}$ ano, que, até então, tivera contato apenas com a metodologia tradicional de ensino e, por isso, apresentaram certa relutância à nova metodologia; entretanto, ao final da pesquisa, foram apontados bons resultados com relação à implementação das atividades investigativas nessa turma.

Assim, mediante as discussões e críticas dos participantes do grupo de estudos, foram coletados dados em áudio e respostas a um questionamento, onde foi possível

\footnotetext{
${ }^{1}$ Disponível em: 〈http://www.if.ufrgs.br/ienci/artigos/Artigo_ID311/v17_n3 a2012.pdf>. Acesso em: 25 out. 2017.
} 
coletar argumentos para subsidiar as seguintes indagações: Como os professores refletem acerca do uso de atividades investigativas no ensino de ciências? Em algum momento já contemplaram este tipo de ensino em sua prática?

\section{RESULTADOS E DISCUSSÃO}

Após a transcrição das falas dos participantes buscou-se averiguar a compreensão dos mesmos a respeito das atividades investigativas desenvolvidas nas aulas de Ciências, a partir da leitura do artigo "Implementação de atividades investigativas na disciplina de Ciências em escola pública: Uma experiência didática”. As discussões foram iniciadas questionando os participantes se eles haviam observado durante a leitura do artigo, a presença de interações discursivas entre o professor/pesquisador e os alunos, as respostas foram:

$\mathrm{Na}$ verdade eles quiseram tirar leite de pedra. Porque na realidade, como a criança vai pensar nessa questão se ela não tem nada em que se basear, porque só dizer pra ela o que é um ser vivo o que não é não dá subsídios suficientes pra ela poder pensar nas condições de vida de cada uma, na especificidade de cada uma não da pra você cobrar isso dela? (P6).

[...] mas, nem tinha atingido ainda o objetivo de entender o que é ser vivo e um não vivo [...] (P6).

[...] aqui no primeiro encontro, tivemos uma interação [...] tem a interação entre o professor e os alunos (P9).

Sim, mas ai não foi o suficiente porque se lá no final do trabalho teve aluno que não teve ainda condições de diferenciar bióticos e abióticos [...] (P6).

Primeiro que não era o professor da sala, ai já não vai ter uma interação (P10).

Analisando as falas, foi possível perceber que as interações entre professor/pesquisador e alunos, tão fundamentais no ensino por investigação, não foram observadas de maneira satisfatória. No discurso dos participantes, a professora, que também era a responsável pela pesquisa, não propiciou condições suficientes para que os alunos pudessem diferenciar seres bióticos e abióticos, e as questões problema foram feitas de forma aleatória.

Em se tratando do tema interações discursivas em sala de aula, Sasseron (2013) discorre que é preciso tomar parcimônia para que uma discussão com desfecho rico e 
cheio de argumentações não acabe como uma conversa informal e sem embasamento teórico e científico. Ainda nas palavras da autora, em sala de aula, para que uma interação discursiva ocorra com sucesso, é necessário que o professor saiba explanar com propriedade sobre o conteúdo que está ministrando e, também, saiba ouvir os questionamentos dos alunos, confrontando as ideias. Acredita-se que os participantes da pesquisa não conseguiram visualizar tais pontos no artigo em pauta, e também não se atentaram que foi a primeira vez que os alunos da turma analisada tiveram contato com uma atividade investigativa, demonstrando, assim, certa recusa ao novo, pois estavam acostumados com o ensino tradicional no qual o apenas o professor "transmitia" o conteúdo. Assim, o esforço da professora/pesquisadora em promover um ambiente investigativo, evidente no artigo, não foi notado pelo grupo.

Dando sequência, os professores foram indagados a respeito da quantidade de aulas (sete aulas de 50 minutos), e se eles achavam o montante suficiente para ministrar conteúdos de fotossíntese e respiração. Os argumentos foram:

É, eu acho que é [...] pra ver o desenvolvimento, é claro, que o terrário está errado [...] (P9).

Eu acho que não [...] pra desenvolver um terrário [...] (P5).

[...] o terrário seria a exemplificação da questão. Então ele teria que primeiro entender o processo, para depois ele verificar o processo na prática, eu não sei se eu estou errada. Mas, eu penso assim, dai você vai querer fazer as duas coisas ao mesmo tempo ele não acompanha, é muita informação (P6).

De acordo com os excertos, para a maioria dos integrantes da pesquisa, o tempo de sete aulas não seria adequado para ministrar os conteúdos de forma investigativa. Averiguou-se que alguns integrantes do grupo não compreenderam que a professora/pesquisadora levou para sala de aula o terrário já pronto, explicando aos alunos do $6^{\circ}$ ano como foi montado e pedindo que com o auxílio de uma tabela, fossem observando e anotando as modificações no decorrer das aulas e propondo hipóteses.

Com esta análise, é possível deduzir que uma parcela dos professores ainda vislumbra uma metodologia tradicional, no qual a teoria e prática estão dissociadas. Libâneo (2001) pontua ser contrário à metodologia tradicional, por ela ser mecânica e repetitiva, focada apenas na memorização dos alunos e na fala do professor. Para o autor 
“[...] a aprendizagem duradoura é aquela pela qual os alunos aprendem a lidar de forma independente com os conhecimentos" (LIBÂNEO, 2001, p. 1).

Embora o artigo apresente resultados positivos com relação ao desenvolvimento da atividade investigativa, tais como: levantamento de hipóteses pelos alunos, capacidade de argumentar e ouvir as explicações dos colegas, os integrantes do grupo de estudos pouco valorizaram a proposta destas atividades, como fica evidente nas falas apresentadas. Isto demonstra, mais uma vez, que eles estão pouco susceptíveis a mudanças na prática educativa, ou ainda possuem oposição a novas estratégias pedagógicas.

Continuando as arguições, indagou-se o grupo quanto à participação dos alunos, que de acordo com a metodologia investigativa deve ser valorizada, a resposta que mais se sobressaiu foi:

Então, para ser investigativo ele teria que ir buscar essas respostas, não é? Não é só ficar em cima do "achomêtro" [...] No final das contas a gente fala que é investigativo, mas ele não se caracteriza, porque ele não foi à busca de nenhuma informação né? Nós ficamos só em cima do que você acha, do que você sabe, só foi constatado que os alunos não sabiam, mas isso eles não tinham que saber mesmo (P6).

Neste caso, pode-se perceber, mais uma vez, que o participante demonstra oposição às atividades de cunho investigativo, e possivelmente não considera a importância da valorização do conhecimento prévio dos alunos. Conforme Carvalho (2004), os alunos já trazem para a sala de aula alguns conceitos estruturados, nenhum aluno chega à escola como uma "tábula rasa", como se pensava antigamente. E é essa bagagem cotidiana que a escola deve valorizar no processo de aprendizagem, com o intuito de formar o conhecimento científico.

As atividades foram finalizadas solicitando aos participantes para discorrerem por escrito, se em algum momento eles já contemplaram, em suas aulas e/ou estágios, atividades investigativas, e algumas das respostas foram:

Busco sempre que possível, trabalhar com o Ensino por investigação e atividade investigativas, mas só agora estou aprendendo que o tempo, ou melhor, a falta de aulas, não é um problema para trabalhar com este ensino (P1). 
Há duas semanas eu trabalhei com meus alunos uma atividade investigativa em duas aulas, sobre ácidos e bases. Dada uma situação problema (no caso, eles deveriam sugerir uma maneira de se verificar se um dado solo era ácido para garantir o plantio de uma safra de feijão), os alunos foram levados a construir os conceitos de ácido e base em nível operacional, para posteriormente sugerirem uma resolução à problemática em questão (P3).

Sim já utilizei em várias aulas. Em uma aula sobre fungos. Aproveitei a curiosidade dos alunos sobre o fungo presente numa laranja, solicitei que eles explicassem como surgiu o fungo na laranja, alguns simplesmente responderam que a laranja apodreceu por isso aparece o fungo, outros responderam que o fungo era o caldo da laranja, após as colocações sugeri um experimento de observação, que durou seis aulas, neste período realizaram uma pesquisa sobre fungos, observaram as variedades de fungos existentes no pátio do colégio, diferenciaram musgos de fungos e liquens, observaram em laboratório os fungos identificaram os esporos e as partes que compõe o fungo. (P5).

Dos dez participantes da pesquisa, sete disseram contemplar atividades investigativas em suas aulas e/ou estágios, principalmente, ao abordar temas que possibilitam a discussão de questões sociais.

Este surpreendente desfecho, nos permite deduzir que uma parcela considerável, tanto dos professores quantos dos licenciandos, trabalha com atividades investigativas, mesmo que de forma pontual. Em conformidade com Carvalho et al. (1998), os professores precisam incitar em seus alunos a busca de novas competências e habilidades, assim, inovando os métodos de ensinos.

É oportuno salientar, que os licenciandos do curso de Química demonstraram maior embasamento para contemplar o ensino por investigação em situações de aprendizagem. De acordo com Oliveira (2013), os cursos de formação inicial e continuada devem possibilitar a seus alunos oportunidades de reflexões sobre o ensino de ciências, com vistas ao questionamento e a adaptações ao meio social. Só assim, serão formados professores com pouca ou nenhuma dificuldade para elaborar aulas de qualidade e de acordo com a realidade de seus alunos.

E, apesar das críticas feitas ao artigo pelos participantes do grupo de estudos, o que é compreensível, por se tratar de professores com média de tempo de docência de 22,5 anos, com exceção dos licenciandos, formados em uma racionalidade técnica, supostamente por isso a objeção em aceitar metodologias de ensino que deem voz ao aluno. Porém, as críticas e dificuldades foram sendo amenizadas no decorrer dos encontros do grupo de estudos. Espera-se que estes professores se sintam motivados, 
após a experiência vivenciada no grupo, e comecem a lançar mão dessa metodologia em suas práticas.

Compreende-se também, que é difícil para alguns professores aderirem ao novo, tendo em vista que passaram tantos anos desenvolvendo a mesma metodologia tradicional de ensino. No entanto, renovar é preciso, até mesmo para que esses professores possam buscar novas expectativas em suas carreiras profissionais. Em concordância com Carvalho et al. (1998, p. 28), o professor é a peça fundamental no ensino por investigação e, em virtude desse fato, essa metodologia de ensino apresenta vantagens com relação ao ensino tradicional, em que podemos destacar: "[...] a autonomia do aluno; a cooperação entre os alunos; o papel do erro na construção do conhecimento; a avaliação; a interação entre professor aluno".

\section{CONSIDERAÇÕES FINAIS}

Mediante a análise dos dados obtidos e da interlocução com os referenciais teóricos, alguns resultados parciais destacaram-se: parte dos professores do grupo de estudos demonstrou uma visão um tanto quanto tradicionalista em relação ao ensino de ciências; pouca abertura aos conhecimentos prévios trazidos pelos alunos; a não aceitação dos alunos como atores principais no processo de ensino e aprendizagem; críticas com relação à quantidade de aulas (tempo); resistência à inserção de novas estratégias pedagógicas.

Assim, pode-se refletir a respeito da importância de cursos de formação continuada que proporcionem aos professores reflexões significativas sobre suas práticas pedagógicas, bem como, a interação com metodologias de ensino vigentes. Ressalta-se, também, que a experiência vivenciada, por meio desta pesquisa, foi relevante pela interação/integração estabelecida entre pós-graduanda, professores universitários, professores da rede pública de ensino e licenciandos, atuando como uma forma de se minimizar problemas relacionados à formação docente.

Acredita-se que com a inserção de atividades investigativas mais frequentes, os professores poderão despertar o interesse em seus alunos. Entende-se que esta proposta 
realmente demanda tempo, porém, a construção do conhecimento por parte dos alunos pode ser expressiva e compensatória.

Nesta perspectiva, é possível dizer que os participantes do grupo de estudos "ensino por investigação em ciências" apresentam potenciais para proporcionar a seus alunos aulas com atividades investigativas, distanciando-se da prática tradicional. Porém, para que isso ocorra é necessário tempo e investimentos no processo de formação continuada do professor, de modo a desencadear reflexões acerca da prática pedagógica, no sentido de reconstruí-la.

\section{REFERÊNCIAS}

AZEVEDO, M. N. Pesquisa-ação e atividades investigativas na aprendizagem da docência em Ciências. 2008. 224 f. Dissertação (Mestrado) - Faculdade de Educação da Universidade de São Paulo, Universidade de São Paulo, São Paulo, 2008.

BORGES, R. C. P. Formação de formadores para o ensino de ciências baseado em investigação. 2010. 257 f. Tese (Doutorado) - Programa de Pós-Graduação em Educação: Ensino de Ciências e Matemática, Faculdade de Educação da Universidade de São Paulo, São Paulo, 2010.

BRASIL. Secretaria da Educação Fundamental. Parâmetros Curriculares Nacionais: Ciências Naturais: terceiro e quarto ciclos do Ensino Fundamental. Brasília: MEC/SEF, 1998. 138 p. Disponível em: 〈http://portal.mec.gov.br/seb/arquivos/pdf/ciencias.pdf>. Acesso em: 23 out. 2017.

CARVALHO. A. M. P et al. Ciências no ensino fundamental: o conhecimento físico. São Paulo: Scipione, 1998.

CARVAlHO. A. M. P. Critérios estruturantes para o ensino de Ciências. In: CARVAlHO. A. M. P (Org.). Ensino de Ciências: unindo a pesquisa e a prática. São Paulo: Pioneira Thomson Learning, 2004. p. 1-17.

CARVALHO. A. M. P. O ensino de Ciências e a proposição de sequências de ensino investigativas. In: CARVALHO. A. M. P (Org.). Ensino de ciências por investigação: 
condições para a implementação em sala de aula. São Paulo: Cengage Learning, 2013. p. $1-20$.

CARVALHO, A. M. P.; GIL-PÉREZ, D. Formação de professores de ciências: tendências e inovações. 10. ed. São Paulo: Cortez, 2011.

DelizOICOV, D.; ANGOTTI, J. A.; PERnAMBUCO, M. M.. Ensino de Ciências: fundamentos e métodos. São Paulo: Cortez, 2002.

GARCIA, M. C. Formação de professores: para uma mudança educativa. Porto, Portugal: Porto Editora, 1999.

LEITE, J. C. Ensino por Investigação: reflexões de professores de Ciências em um processo de formação continuada. 2015. 145 f. Dissertação (Mestrado) - Programa de Pós-Graduação em Educação para a Ciência e a Matemática, Universidade Estadual de Maringá, Maringá, 2015.

LEITE, J. C.; MAGAlHÃES JÚNIOR, C. A. O.; RODRIGUES, M. A. Ensino por investigação: o que dizem os professores de Ciências. Revista da SBEnBio, n. 9, p. 5144- 5154, dez./2016.

LIBÂNEO, J. C. O essencial da didática e o trabalho de professor - em busca de novos caminhos. Goiás: Pontifícia Universidade Católica de Goiás, UCG, 2001. Disponível em: <http://limaribeiro.net/File/Content/Document/pt-br/didatica-do-ensinosuperior-o-essencial-da-didatica.pdf>. Acesso em: 28 out. 2017.

LIBÂNEO, J. C.; PIMENTA, S. G. Formação de profissionais da educação: Visão crítica e perspectiva de mudança. Educação \& Sociedade, Campinas, v. 20, n. 68, p. 239-277. dez. 1999.

MAGAlHÃES JÚNIOR, C. A. O.; PIETROCOLA, M.; ORTÊNCIO FILHO, H. História e características da disciplina de ciências no currículo das escolas brasileiras. Educere - Revista da Educação, v. 11, n. 2, p. 197-224, jul./dez. 2011.

MINAYO, M. C. S. O desafio do conhecimento: pesquisa qualitativa em saúde. 4. ed. São Paulo: Hucitec-Abrasco, 1996.

MUNFORD, D.; LIMA, M. E. Ensinar ciências por investigação: em quê estamos de acordo? Revista ensaio. v. 9, n.1, p. 98-111, jan. 2007. 
OLIVEIRA, A. L. Um estudo sobre a formação inicial e continuada de professores de ciências: o ensino por investigação na construção do profissional reflexivo. 2013. 231 f. Tese (Doutorado) - Programa de Pós-Graduação em Educação para a Ciência e a Matemática - Universidade Estadual de Maringá, Maringá, 2013.

SÁ, E. F. Discursos de professores sobre ensino de Ciências por investigação. 2009. 202 f. Tese (Doutorado) - Programa de Pós-graduação em Educação da Universidade Federal de Minas Gerais - Universidade Federal de Minas Gerais, Belo Horizonte, 2009.

SASSERON, L. H. Interações discursivas e investigação em sala de aula: o papel do professor. In: CARVALHO, A. M. P. (Org.). Ensino de ciências por investigação: condições para a implementação em sala de aula. São Paulo: Cengage Learning, 2013. p. 41-62.

SASSERON, L. H.; CARVALHO, A. M. P. Almejando a alfabetização cientifica no ensino fundamental: A proposição e a procura de indicadores do processo. Investigações em Ensino de Ciências, v. 12, n. 3, p. 333-352, 2008.

SASSERON, L. H.; LETTA, L. Elementos do ensino de ciências por investigação: consideração do papel do professor para a promoção da alfabetização científica em sala de aula. In.: MAGALHÃES JÚNIOR, C. A. O.; CORAZZA, M. J.; LORENCINI JÚNIOR, A. (Orgs.) - prefácio Roberto Nardi. Formação de professores de ciências: perspectivas e desafios. Maringá: Eduem, 2017. p. 115-132.

SCHNETZLER, R. P. Concepções e alertas sobre Formação continuada de professores de Química. Química Nova na Escola. São Paulo, n. 16, p. 15-20, nov. 2002.

ZÔMPERO, A. F.; LABURÚ, C. E. Atividades investigativas no Ensino de Ciências: aspectos históricos e diferentes abordagens. Revista Ensaio, Belo Horizonte, v.13, n. 3, p. 67-80, set./dez. 2011.

ZÔMPERO, A. F.; LABURÚ, C. E. Implementação de atividades investigativas na disciplina de Ciências em escola pública: uma experiência didática. Investigações em Ensino de Ciências, Porto Alegre, v. 17, n. 3, p. 675-684, dez. 2012. 